Obstetrics

\title{
Role of ultrasonography in the management of twin gestation
}

\author{
Jessica Smith* | Marjorie C. Treadwell | Deborah R. Berman
}

Department of Obstetrics and

Gynecology, University of Michigan Medical

School, Ann Arbor, MI, USA

\section{${ }^{*}$ Correspondence}

Jessica Smith, Department of Obstetrics and Gynecology, University of Michigan,

Ann Arbor, MI, USA.

Email: ntonavol@med.umich.edu

\begin{abstract}
Twins represent $1 \%-2 \%$ of all pregnancies, yet continue to account for a disproportionate share of neonatal adverse events including neonatal intensive care admission, morbidity, and mortality. Ultrasonography is central to the proper diagnosis of the type of twinning. Ideally, ultrasonography is performed before 14 weeks of gestation to determine chorionicity and amnionicity. Correct identification of the chorionicity in a twin pregnancy facilitates proper counseling and management of the gestation, including ultrasonography follow-up. Herein, the different types of twinning are reviewed, together with the implications for ultrasonography monitoring of each specific type of twin gestation.
\end{abstract}

\section{KEYWORDS}

Congenital anomalies; Conjoined twins; Dizygotic twins; Fetal death; Intrauterine fetal growth restriction; Monozygotic twins; Twin pregnancy; Twin-to-twin transfusion syndrome

\section{1 | INTRODUCTION}

The increasing incidence of twin pregnancies reinforces the need for clinicians to understand the appropriate evaluation and management of multiple gestations. Ultrasonography is integral for appropriate diagnosis and surveillance, facilitating the optimization of care for the pregnancy.

The rate of twins in high-income countries ranged from 14.6 to 21.2 per 1000 deliveries in $2011 .{ }^{1}$ Twins are responsible for a disproportionate share of pregnancy-related complications. Most adverse events relate to the high risk of prematurity; in Europe, the median preterm delivery rate ( $<37$ weeks of gestation) in multiples is $53 \%$ and among very preterm deliveries (<32 weeks) is $9 \% .{ }^{2}$ Additional problems are related to growth anomalies, discordant fetal anomalies, or the many potential adverse events of monochorionic twinning, all of which can be detected by prenatal imaging. The role of ultrasonography in the accurate diagnosis and management of twin gestations is explored in the present review.

\section{2 | ETIOLOGY OF TWINS}

Twins develop either from two fertilized eggs implanting into the uterus (dizygotic) or from a single fertilized egg that splits early in pregnancy (monozygotic). Although most twins are dizygotic, one-third are monozygotic or "identical". ${ }^{3}$ All dizygotic twins have functionally separate placentas and are dichorionic/diamniotic. Dizygotic twins carry less risk than monozygotic twins; however, the risk is greatest for monozygotic twins that share a placenta (monochorionic). Ultrasonography cannot always clarify zygosity. Dichorionic twins with discordant genders are known to be dizygotic. However, the zygosity of dichorionic same-gender twins is not obvious because $30 \%$ of monozygotic twins are dichorionic. ${ }^{4}$

For monozygotic twins, the day on which the embryo splits after fertilization determines chorionicity (Table 1). ${ }^{3}$ An embryo splitting on day 1-3 after fertilization results in dichorionic/diamniotic twins. If the

TABLE 1 Time of splitting in cases of monozygotic twinning. ${ }^{a}$

\begin{tabular}{|c|c|c|}
\hline $\begin{array}{l}\text { Embryo } \\
\text { splitting } \\
\text { time, d }\end{array}$ & $\begin{array}{l}\text { Frequency in } \\
\text { spontaneous twin } \\
\text { pregnancy, \% }\end{array}$ & Placentation \\
\hline $1-3$ & 30 & Dichorionic/diamniotic \\
\hline $4-7$ & 70 & Monochorionic/diamniotic \\
\hline $8-12$ & $<2$ & Monochorionic/monoamniotic \\
\hline $13-16$ & $<1$ & Conjoined twins \\
\hline
\end{tabular}

${ }^{\mathrm{a} D}$ Data from Benirschke et al. ${ }^{3}$ 
embryo splits on day 4-7, monochorionic/diamniotic twins develop. Splitting on day 8-12 leads to monochorionic/monoamniotic twins; less than $2 \%$ of monozygotic pregnancies are monoamniotic. Conjoined twins result from the embryo splitting 13-16 days after conception.

Approximately $80 \%-90 \%$ of spontaneously conceived twin pregnancies are dichorionic. ${ }^{4}$ The incidence of monochorionic twins is higher among pregnancies achieved by assisted reproductive technology, especially in vitro fertilization, and is even higher among those resulting from transfer of day 5 blastocysts. ${ }^{5}$

\section{3 | CHORIONICITY AND AMNIONICITY}

Identifying chorionicity in the first trimester is extremely important. The number of chorions (placentas) and amnions (inner membranes covering the embryo) has the largest impact on both pregnancy risk and determination of the management for that gestation.

Chorionicity is best determined by ultrasonography before 14 weeks of gestation and has an accuracy of $99 \% .^{6,7}$ In a dichorionic pregnancy at less than 8 weeks of gestation, the two gestational sacs can appear completely separated (Fig. 1). ${ }^{8}$ The appearance of the placentas for dizygotic twins between 8 and 14 weeks depends on the location of placental implantation. ${ }^{9}$ If the placentas implant away from each other, they will have the appearance of two distinct placentas. Separate placentas can be seen in approximately one-third of twin gestations. ${ }^{9}$ However, if the implantations occur close together, the placentas can appear fused, similar to a single placenta with a twin peak or lambda sign seen in the intervening membrane (Fig. 2). ${ }^{8,10}$

The presence of a single chorion in monochorionic twins can be easily identified throughout the first trimester (Fig. 3). ${ }^{8}$ The intervening membrane, created by two amnions (Fig. 4), is more challenging to visualize and sometimes is not identifiable in the early first trimester. ${ }^{11,12}$ If the amnion is not identified in early gestation, follow-up

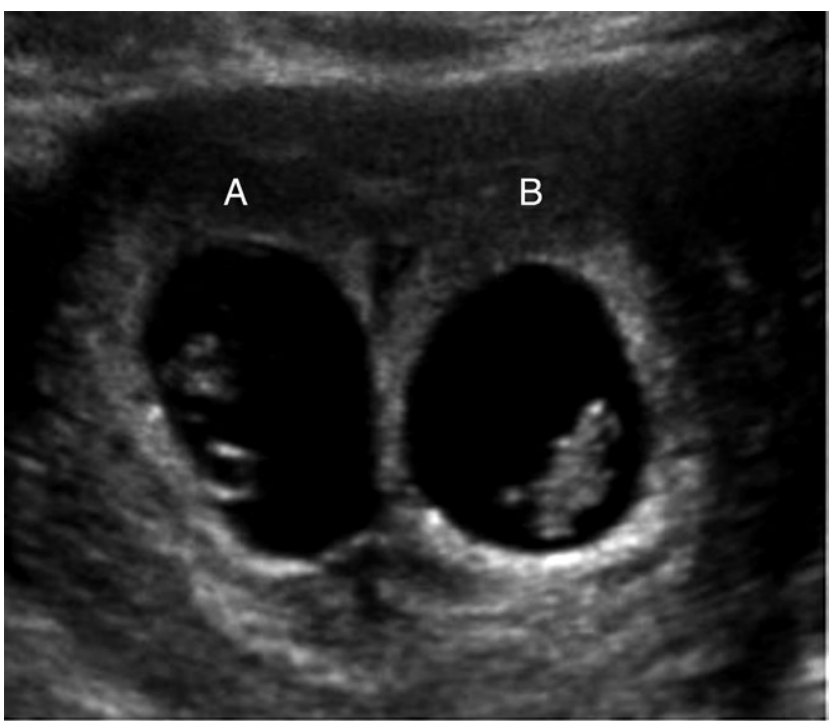

FIGURE 1 Dichorionic pregnancy at 7 weeks of gestation. Note the thick echogenic chorion surrounding each embryo and between the embryos, labeled A and B.

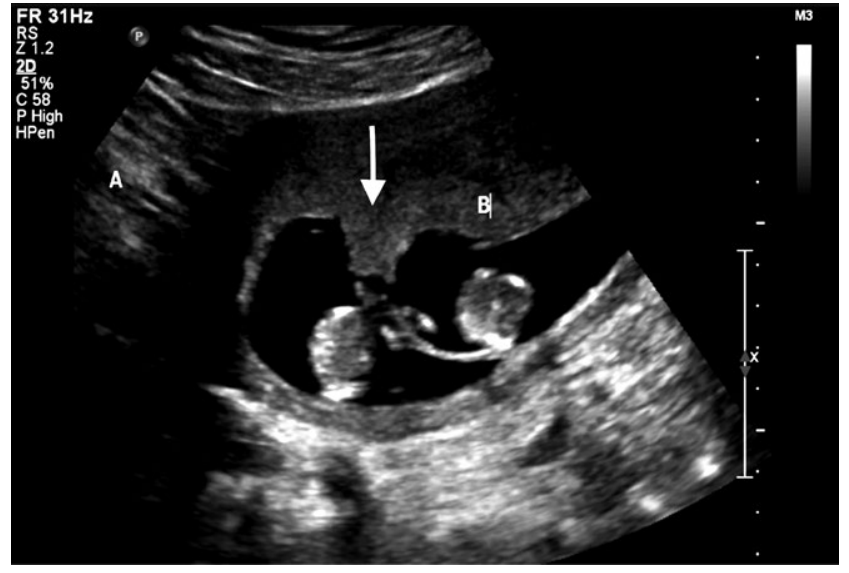

FIGURE 2 Twin peak (lambda) sign in a dichorionic pregnancy. Arrow indicates the twin peak, which separates the two embryos labeled A and B. Note the extension of the placenta into the intervening membrane.

ultrasonography should be performed before 14 weeks of gestation to confirm amnionicity. The presence of a T sign where two opposing amnions meet at the edge of the placenta is diagnostic of a diamniotic/monochorionic gestation (Fig. 5). ${ }^{13}$ The inability to identify an intervening membrane, along with the presence of intertwined umbilical cords, confirms a monochorionic/monoamniotic pregnancy (Figs 6 and 7).

If an ultrasonography examination has not been performed before 14 weeks of gestation to determine chorionicity, ultrasonography determination of chorionicity should be attempted at the time of presentation. In approximately $14 \%$ of dichorionic pregnancies, the lambda sign will disappear by 20 weeks of gestation ${ }^{14}$; however, in the majority of cases, it will still be visible. Ultrasonography determination of chorionicity in the second trimester ( $<24$ weeks) has a positive predictive value of $95 \% .{ }^{15}$ In addition to the lambda sign, sex can be used

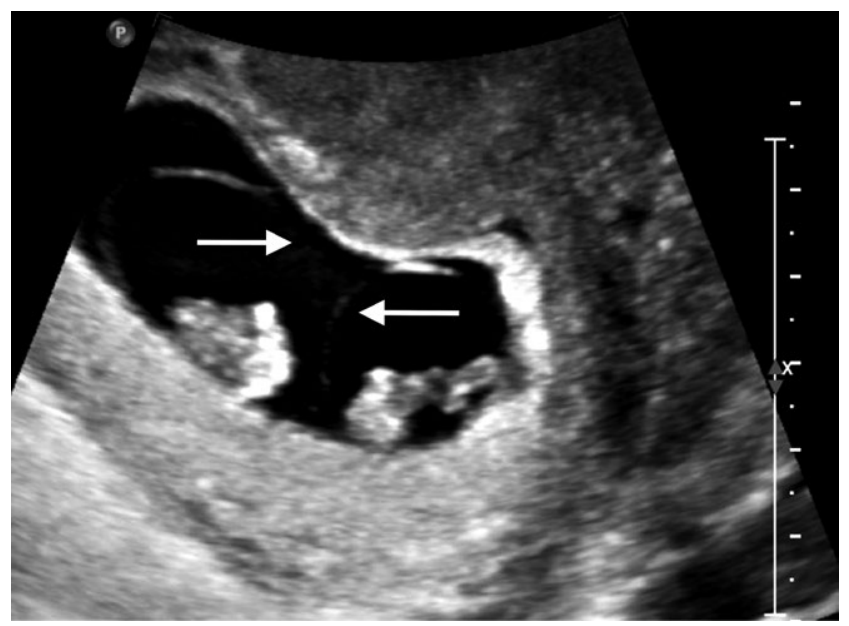

FIGURE 3 Diamniotic/monochorionic pregnancy at 6-7 weeks of gestation. The single chorion and two separate amnions (indicated by arrows) are visible. Note the absence of placenta extending into intervening membrane. 


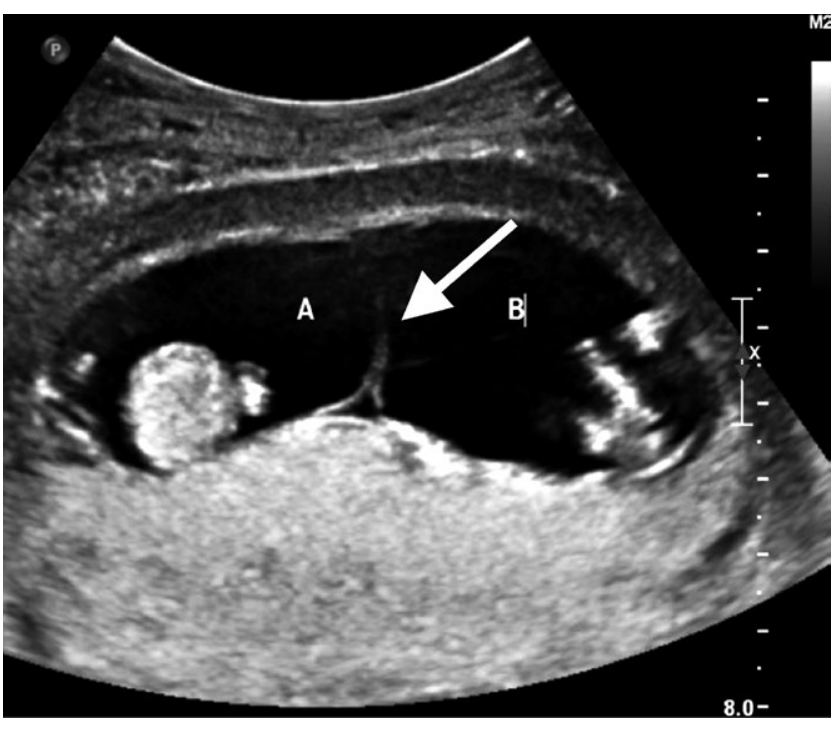

FIGURE 4 Diamniotic/monochorionic pregnancy in the first trimester. Arrow indicates the intervening diamniotic membrane separating the two embryos, labeled A and B.

to determine chorionicity. Except in rare cases, different fetal sexes imply dichorionic twins.

The number of placentas is more challenging to assess as pregnancy progresses. Two separate placentas usually represent dichorionic twins. In approximately $3 \%$ of monochorionic twins, however, the placenta appears as two separate masses ${ }^{16}$; in addition, dichorionic placentas can fuse. Dichorionic twins have four intervening membranes (two chorions and two amnions) as compared with two intervening membranes (two amnions) in monochorionic twins. Although membrane thickness has been proposed as a method to determine chorionicity, it is a poor single predictor of chorionicity, with a specificity of only $85 \%$ based on a cut-off membrane thickness of $2 \mathrm{~mm}$ or

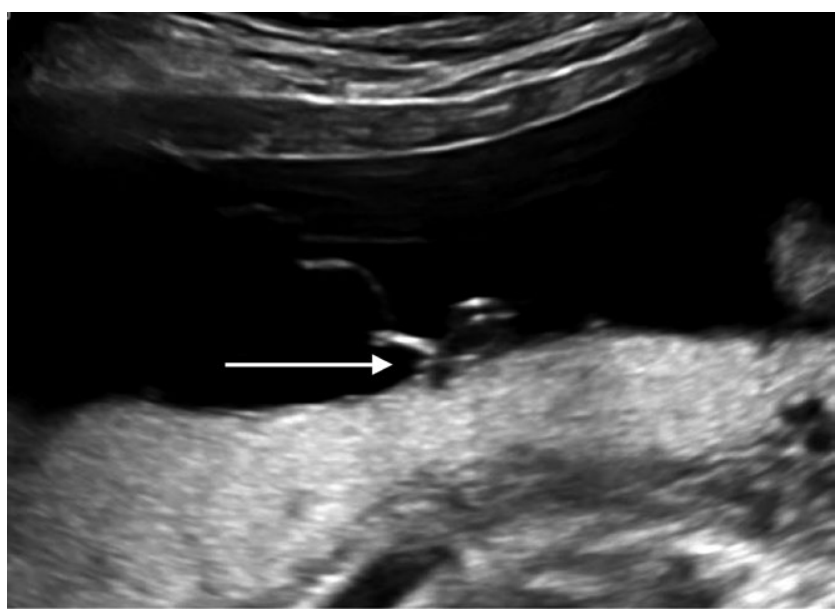

FIGURE 5 T sign in a diamniotic/monochorionic twin gestation. Note the absence of chorion extending between the layers of the intertwin membrane, which comes to an abrupt halt at the edge in a T configuration (indicated by arrow).

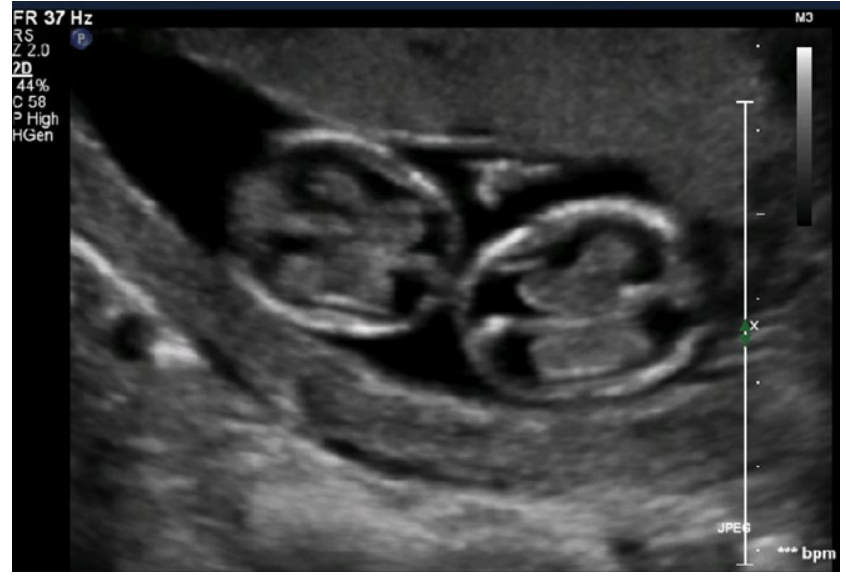

FIGURE 6 Monoamniotic/monochorionic pregnancy at 13 weeks of gestation. There is no intervening membrane and the fetal calvariae are immediately adjacent to each other.

more. ${ }^{17}$ If the chorionicity of the pregnancy cannot be determined, the pregnancy should be classified as "presumed monochorionic," and monitored and managed as such for the remainder of the gestation.

Not only is early ultrasonography crucial for assessing chorionicity, but it is also recommended for accurate pregnancy dating. As in singleton pregnancies, if the crown rump length (CRL) is consistent with a sure last menstrual period (LMP), the LMP should be used for pregnancy dating. The larger CRL should be used for dating if the CRLs of the two fetuses are discordant. ${ }^{18}$ If the first ultrasonography examination is not performed until after 14 weeks, biometric parameters should be used to determine gestational age rather than CRL. ${ }^{19}$ Again, the larger head circumference should be used to determine pregnancy dating if the biometric parameters of the two fetuses are discordant. ${ }^{18}$ Correct chorionicity and accurate pregnancy dating are both important in assisting the correct timing and interpretation of screening tests, diagnostic tests, and timing of delivery.

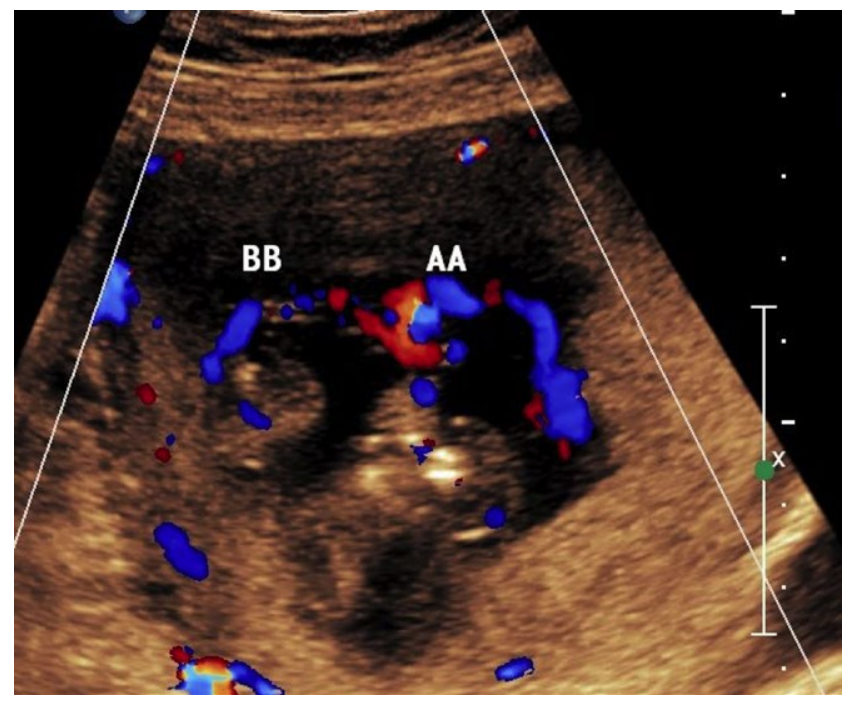

FIGURE 7 Cord entanglement in a monoamniotic/monochorionic pregnancy. The twins' cords are labeled AA and BB. 


\subsection{Diamniotic/dichorionic twins}

Dichorionic/diamniotic gestation and pregnancy dating are ideally determined in the first trimester. Aneuploidy screening should be offered in twin gestations just as in singleton gestations. Although its detection rates are lower than those observed for singleton pregnancies, first-trimester combined screening by nuchal translucency and serum analytes (free $\beta$-human chorionic gonadotropin, pregnancy associated-plasma protein-A) has a detection rate for Down syndrome of $70 \%-72 \%$ with a $5 \%$ false-positive rate for twins. ${ }^{20}$ Cell-free DNA screening is also available for twin gestations. ${ }^{21}$ The American Congress of Obstetricians and Gynecologists does not recommend the use of cell-free DNA screening in multiple gestations ${ }^{22}$; however, the American College of Medical Genetics recommends discussing the validity of cell-free DNA screening with the laboratory before offering the test to women with multiple gestations. ${ }^{23}$

Routine anatomic evaluation should be performed at the same gestational age applied to singletons. Dichorionic twins have a slightly higher rate of fetal anomalies (3\%) as compared with singletons (2\%). ${ }^{24}$ Placenta previa is more common in dichorionic gestations; this is probably due to the increased placental mass. ${ }^{26}$ In addition to placental location, placental cord insertions should also be evaluated. The rate of velamentous cord insertion ( $\mathrm{VCl}$ ), where the umbilical cord is inserted within the fetal membranes, is $8 \%$ in dichorionic twins. ${ }^{27}$ It occurs in both twins in nearly $1 \%$ of dichorionic twin pregnancies, and has been associated with an increased rate of intrauterine growth restriction. ${ }^{27,28}$ A single umbilical artery, which is also associated with decreased growth, is three times more common in twin than in singleton gestations. ${ }^{29}$

Serial ultrasonography examinations every 4-6 weeks are recommended to assess fetal growth, size concordance, and amniotic fluid volume. ${ }^{18}$ Growth discordance is calculated by the difference in the estimated twin weights divided by the weight of the larger twin, and is expressed as a percentage. Although variations in the definition of discordance range from $18 \%$ to $25 \%$, in general, a growth discordance greater than $20 \%$ is associated with a higher incidence of adverse outcomes. ${ }^{18,30}$ Discordant growth is seen in $7 \%-18 \%$ of dichorionic gestations and can be related to differential placental mass, cord insertion, placental implantation sites, or underlying differences in genetic growth potential. $^{31}$

\section{2 | Diamniotic/monochorionic twins}

Similar to dichorionic twinning, first-trimester ultrasonography before 14 weeks of gestation is required in monochorionic twins to define chorionicity, date the pregnancy, and facilitate appropriate counseling and management of the pregnancy. ${ }^{6}$ The frequency of complications is higher for monochorionic twins than for dichorionic twins owing to the shared placenta with vascular anastomoses. All monochorionic twins share anastomoses, with differential risks to each twin. In light of these known connections, single intrauterine fetal demise (IUFD) has an impact on the remaining fetus, including 10\%-15\% risk of co-twin demise and $10 \%-30 \%$ chance of neurologic injury. ${ }^{32}$ Placental vascular anastomoses also result in risks that are unique to monochorionic twins. For example, there is $10 \%$ risk of twin-to-twin transfusion syndrome (TTTS), 10\% risk of selective intrauterine growth restriction (sIUGR), 3\% risk of twin anemia polycythemia sequence (TAPS), and $1 \%$ risk of twin reversed arterial-perfusion (TRAP) sequence. ${ }^{30}$ Discordant CRL ( $\geq 10 \%$ ) in the first trimester could be a marker for increased risk of structural or chromosomal anomalies, single IUFD, pregnancy loss, TTTS, or sIUGR. ${ }^{33}$

As in dichorionic twinning, first-trimester screening can be used in monochorionic twinning and has a detection rate for trisomy 21 of approximately $84 \%$ with a $5 \%$ false-positive rate. ${ }^{20}$ Regarding nuchal translucency alone, the rate of positive results is higher for monochorionic twins than for dichorionic twins. ${ }^{34}$ This is thought to be related to the higher incidence of structural anomalies among monochorionic twins, as well as the possible association with TTTS risk. Discordant nuchal translucency findings ( $\geq 20 \%$ ) are more concerning in cases of monochorionic twinning and have a $30 \%$ risk of early fetal death or TTTS. ${ }^{35}$ Cell-free DNA can also be considered for aneuploidy screening in monochorionic gestations. ${ }^{21-23}$

Identification of the cord insertion site into the placenta is important in monochorionic twinning. Not only is $\mathrm{VCl}$ more frequent in monochorionic twinning, but it is also associated with higher risks of sIUGR. ${ }^{28}$ The increased incidence of $\mathrm{VCl}$ results in more frequent vasa previa, highlighting the importance of evaluating fetal vessels traversing near the cervix to rule out this condition in cases of lower uterine segment cord insertion. ${ }^{36}$ Transvaginal ultrasonography can be helpful for confirming or ruling out vasa previa when $\mathrm{VCl}$ is noted at the lower margin of the placenta (Fig. 8).

The incidence of congenital anomalies is approximately two-fold higher in monochorionic twins (approximately 6\%) than in dichorionic twins (approximately $3 \%$ ). ${ }^{24}$ The most frequent anomaly is congenital heart disease, which occurs in approximately $5 \%$ of monochorionic twin pregnancies. ${ }^{37}$ Owing to this increased rate of heart disease, fetal echocardiography is recommended for all monochorionic pregnancies. ${ }^{37,38}$ Despite monozygosity, most anomalies are discordant, with $90 \%$ of twin pregnancy anomalies occurring in only one twin. ${ }^{25}$ When

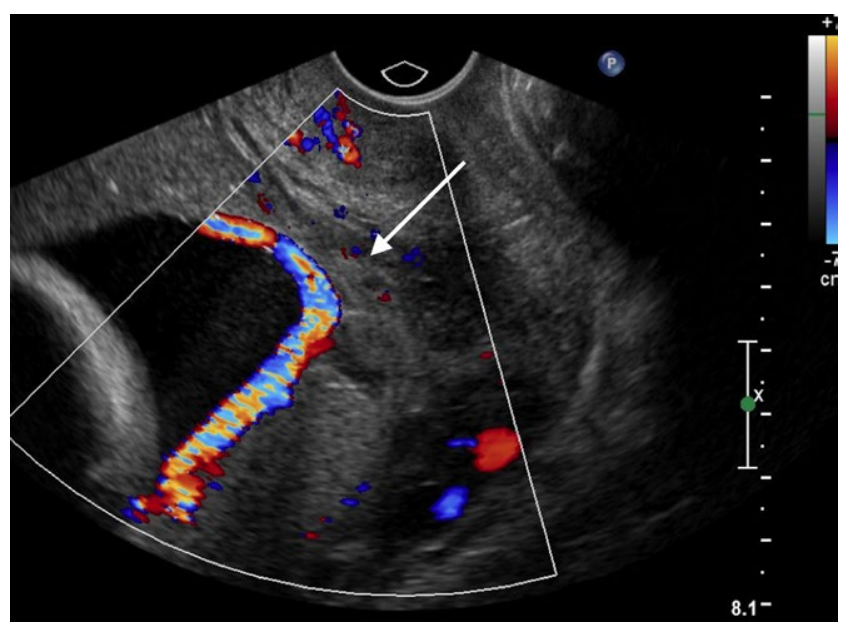

FIGURE 8 Transvaginal ultrasonography of vasa previa. Note the fetal vessels traversing across the internal cervical os (indicated by arrow). 
both twins have anomalies, the same structural anomaly is present approximately $20 \%$ of the time. ${ }^{25}$

Owing to the risk of complications in monochorionic twins, serial ultrasonography examinations should be initiated at 16 weeks of gestation and continued at a minimum of every 2 weeks until delivery. ${ }^{30,39,40}$ Serial scans are performed to evaluate amniotic fluid volume and Doppler velocimetry is used to determine the development of TTTS. Growth should be measured at a minimum of every 4 weeks, with more frequent surveillance or inclusion of umbilical artery Doppler velocimetry when there is discordant fluid, growth discordance or restriction, or other concerns. ${ }^{38}$

\subsection{1 | Twin-to-twin transfusion syndrome}

TTTS occurs in $10 \%$ of monochorionic twins; it is diagnosed by the presence of polyhydramnios in one fetus and oligohydramnios in the co-twin. The donor twin typically appears to be "stuck" to the uterine wall or placenta. Frequently, the intervening membrane is challenging to identify because it is so close to the donor. Errors in assessment can occur if the lack of fluid around the donor is not appreciated (Fig. 9).

Once a diagnosis is made, the stage of TTTS can be determined by using the system developed by Quintero et al. ${ }^{41}$ (Table 2). Stage I is polyhydramnios and oligohydramnios. Stage II is non-visualization of the fetal bladder in the donor twin for more than 60 minutes. Stage III includes pregnancies with abnormal Doppler measurements. Stage IV results when hydrops is present in one or both of the twins. Stage $V$ is the death of one or both fetuses. If an absent bladder, Doppler velocimetry anomaly, or hydrops is observed without both polyhydramnios and oligohydramnios, the diagnosis is not TTTS and other possibilities should be considered, such as sIUGR or a fetal anomaly.

The staging system is helpful for counseling and determining appropriate treatment options. Additional information regarding cardiac function aids in counseling. Identification of placental cord insertions, if not previously performed, is important because proximate

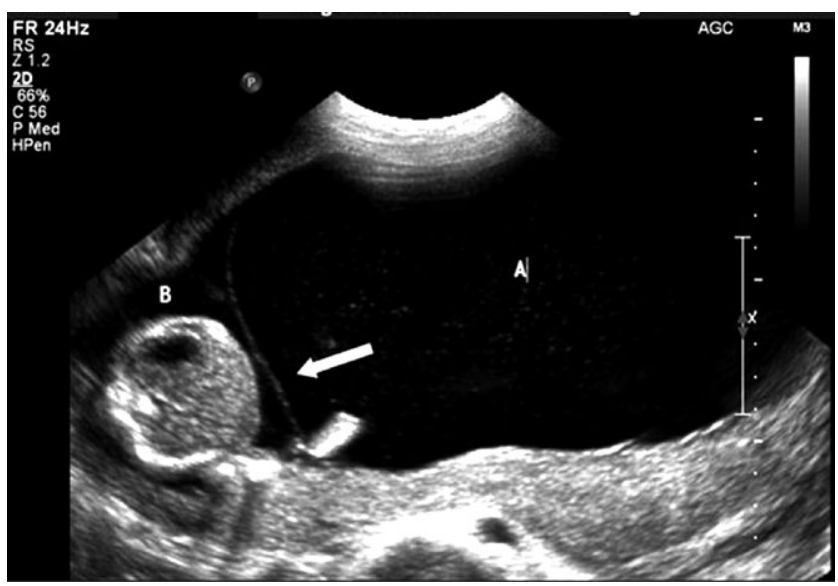

FIGURE 9 Monochorionic/diamniotic twin gestation complicated by twin-to-twin transfusion syndrome. Arrow indicates the intertwin membrane. Polyhydramnios can be seen for fetus $A$, while fetus $B$ demonstrates the "stuck twin" phenomenon with oligohydramnios.
TABLE 2 Classification of twin-to-twin transfusion. ${ }^{a}$

\begin{tabular}{ll}
\hline Stage & Ultrasonography findings \\
\hline 1 & $\begin{array}{l}\text { Polyhydramnios (MVP }>8 \mathrm{~cm} \text { ) in recipient; oligohydramnios } \\
(\mathrm{MVP}<2 \mathrm{~cm} \text { ) in donor }\end{array}$ \\
\hline 2 & Absent bladder in donor for $60 \mathrm{~min}$ \\
\hline 3 & Abnormal Doppler measurements \\
\hline 5 & Hydrops of one or both fetuses \\
\hline
\end{tabular}

Abbreviation: MVP, maximal vertical pocket. ${ }^{a}$ Data from Quintero et al. ${ }^{41}$

cord insertions can preclude fetoscopic laser ablation of the communicating vessels as a treatment option (Fig. 10).

Owing to the high mortality without treatment (73\%-100\%, depending on stage and gestational age at diagnosis), intervention is recommended for TTTS and the most favorable outcomes are achieved with selective fetoscopic laser photocoagulation (sFLP). ${ }^{30,42-44}$ When TTTS is diagnosed, patients should be referred to a fetal therapy center for further counseling on the management of TTTS, including the risks and benefits of sFLP. The sFLP procedure can be performed between 16 and 26 weeks of gestation ${ }^{44}$ and involves laser coagulation of the communicating vessels between the twins to functionally separate the placenta for each twin. ${ }^{44}$ At the end of laser ablation, amnioreduction is performed to normalize the fluid in the recipient twin's sac. ${ }^{44}$

After laser treatment, the pregnancy needs continual close surveillance. Serial ultrasonography examinations should be performed to assess amniotic fluid volume, bladder size, and Doppler velocimetry to monitor for post-laser TAPS, recurrence of TTTS, or IUFD. ${ }^{30}$ Historically, post-laser TAPS has occurred in approximately $10 \%$ of TTTS cases, but the incidence is lower since the introduction of the Solomon technique, which involves coagulation of the whole vascular

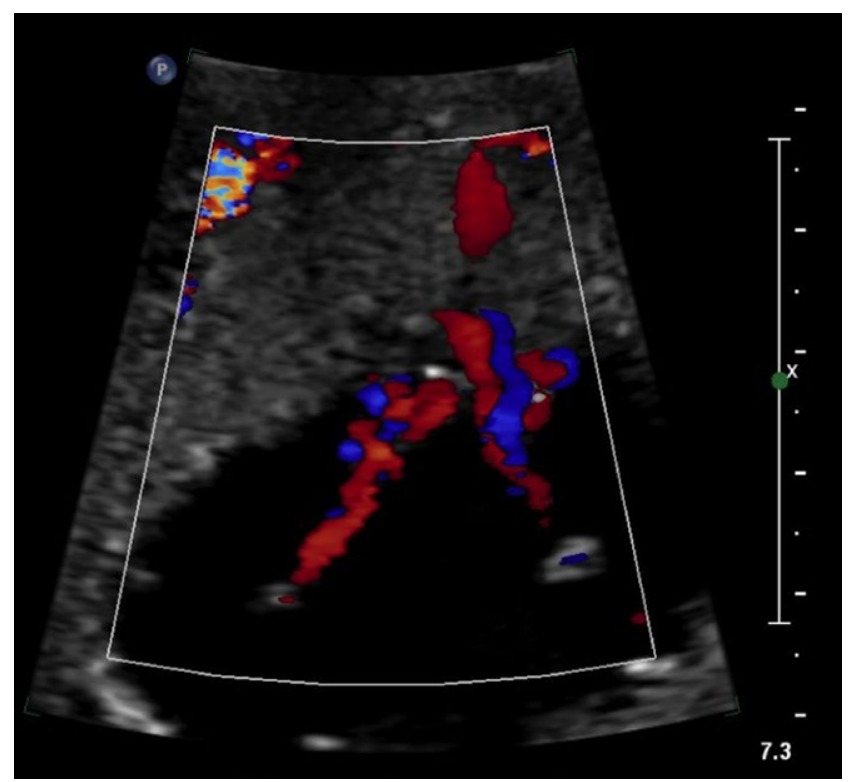

FIGURE 10 Monochorionic twin gestation with proximate cord insertions into the placenta. 
equator to ablate any small vessels or micro-anastomoses that might not be apparent, providing complete functional separation of the portions of the placenta. ${ }^{45}$

Preterm premature rupture of membranes (PPROM) occurs in approximately $30 \%$ of pregnancies that undergo sFLP. ${ }^{46}$ Approximately half of affected women will deliver within 24 hours of PPROM and the mean latency period is 2 weeks. ${ }^{47}$ Unintentional septostomy occurs in approximately $6 \%$ of patients undergoing SFLP; this can convert the pregnancy into a monoamniotic pregnancy with the associated risks. ${ }^{48}$ If there is fetal demise, the surviving co-twin should have an assessment of intracranial structures because ventriculomegaly could be a sign of neurologic damage ${ }^{30,49}$. When membrane separation occurs after sFLP, it is associated with an increased risk of PPROM. ${ }^{50}$

\subsection{2 | Selective intrauterine growth restriction}

sIUGR affects $10 \%$ of monochorionic pregnancies and can be caused by unequal placental sharing, $\mathrm{VCl}$, or discordant splitting of the zygote. ${ }^{51}$ Prognosis is determined by the degree of discordance and the presence or absence of Doppler anomalies. ${ }^{52}$ The same definition of growth discordance used in dichorionic twins applies to monochorionic gestations (intertwin estimated fetal weight discordance ranging from $18 \%$ to $25 \%$, or an estimated fetal weight of less than $10 \%$ for one twin). ${ }^{30}$

Gratacos et al. ${ }^{52}$ have classified monochorionic sIUGR pregnancies as three types. Type I, with positive end diastolic flow in the umbilical artery of the IUGR twin, is associated with $5 \%$ risk of intrauterine demise and intact survival of both twins in more than $90 \%$ of monochorionic sIUGR pregnancies. The average gestational age at delivery is 35 weeks in type I pregnancies. Type II is defined by persistently absent or reversed end diastolic flow in the umbilical artery of the smaller twin (Fig. 11). ${ }^{52}$ Type II has greater discordance (average 38\%) and an earlier mean age of delivery at 31 weeks. ${ }^{52}$ In type III, a variable pattern of intermittently absent or reversed end diastolic flow is interspersed with forward end diastolic flow with a worse prognosis. ${ }^{52}$

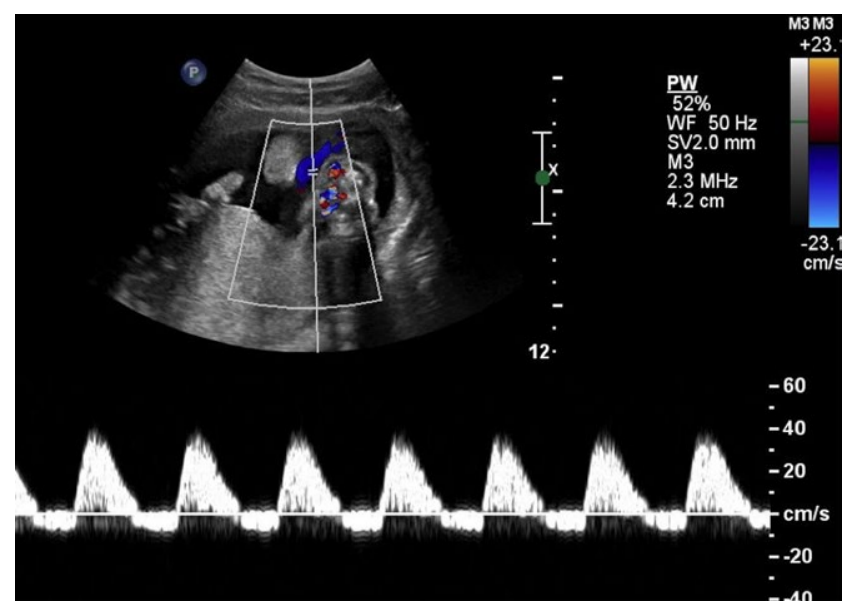

FIGURE 11 Monochorionic/diamniotic twin gestation complicated by reversed end diastolic flow in the umbilical artery, categorized as type II selective intrauterine growth restriction. ${ }^{52}$
The average age at delivery is 31-32 weeks. Unfortunately, in cases of type III sIUGR, prenatal testing is not predictive of fetal demise and there is $21 \%$ risk of IUFD. ${ }^{52}$ In the presence of sIUGR, weekly umbilical artery Doppler velocimetry should accompany prenatal testing to assist in determining the timing of delivery. ${ }^{18}$

\subsubsection{Twin anemia polycythemia sequence}

TAPS is caused by a chronic net transfusion of blood from one fetus to the other, usually through small unidirectional anastomoses within a monochorionic placenta. ${ }^{45}$ TAPS is characterized by significant discordance in hemoglobin levels between monochorionic twins, resulting in discordant peak systolic Doppler velocity of the middle cerebral artery. TAPS occurs spontaneously in approximately $3 \%$ of monochorionic twins, and is most often diagnosed after 26 weeks of gestation. TAPS can also develop after sFLP for TTTS, most commonly 1-5 weeks after the procedure. ${ }^{54}$

Diagnosis requires a Doppler peak systolic velocity of the middle cerebral artery of more than 1.5 multiples of the median in one fetus and less than 1.0 in the co-twin; these findings occur in the absence of polyhydramnios-oligohydramnios, which is diagnostic of TTTS. ${ }^{45}$ The staging for TAPS is summarized in Table $3 .^{45}$ Treatment is dependent on gestational age, but can include continued observation, intrauterine fetal transfusion, sFLP, or delivery with postnatal treatment. ${ }^{45}$ Currently, the best treatment for TAPS has not been established. ${ }^{53}$

\subsubsection{Twin reversed arterial perfusion}

TRAP sequence occurs in $1 \%$ of cases of monochorionic twinning. ${ }^{55} \mathrm{~A}$ pump twin supports the co-twin through unidirectional arterial-arterial anastomosis within the shared single placenta. Deoxygenated blood flows in a retrograde manner from the pump twin into a non-pump twin with abnormal development (Fig. 12). The non-pump twin is typically acephalus and acardiac, with more development of the lower extremities relative to the upper extremities. ${ }^{56}$

Presentation can range from a large amorphous tissue mass to the presence of cranial tissue, a rudimentary heart with cardiac activity, and all four extremities. ${ }^{56}$ Documenting the reversed blood flow in the umbilical artery is key in diagnosis. During first-trimester

TABLE 3 Classification of twin anemia polycythemia sequence. ${ }^{a}$

\begin{tabular}{ll}
\hline Stage & Ultrasonography findings \\
\hline 1 & $\begin{array}{l}\text { PSV of MCA }>1.5 \mathrm{MoM} \text { in donor; } \\
\text { PSV of MCA }<1.0 \mathrm{MoM} \text { in recipient }\end{array}$ \\
\hline 2 & $\begin{array}{l}\text { PSV of MCA }>1.7 \mathrm{MoM} \text { in donor; } \\
\text { PSV of MCA }<0.8 \mathrm{MoM} \text { in recipient }\end{array}$ \\
\hline 4 & Cardiac compromise of the donor (critically abnormal flow) \\
\hline 5 & Intrauterine demise of one or both fetuses preceded by TAPS \\
\hline
\end{tabular}

Abbreviations: PSV, peak systolic velocity; MCA, middle cerebral artery; MoM, multiple of the median; TAPS, twin anemia polycythemia sequence. ${ }^{\mathrm{a}}$ Data from Slaghekke et al. ${ }^{45}$ 


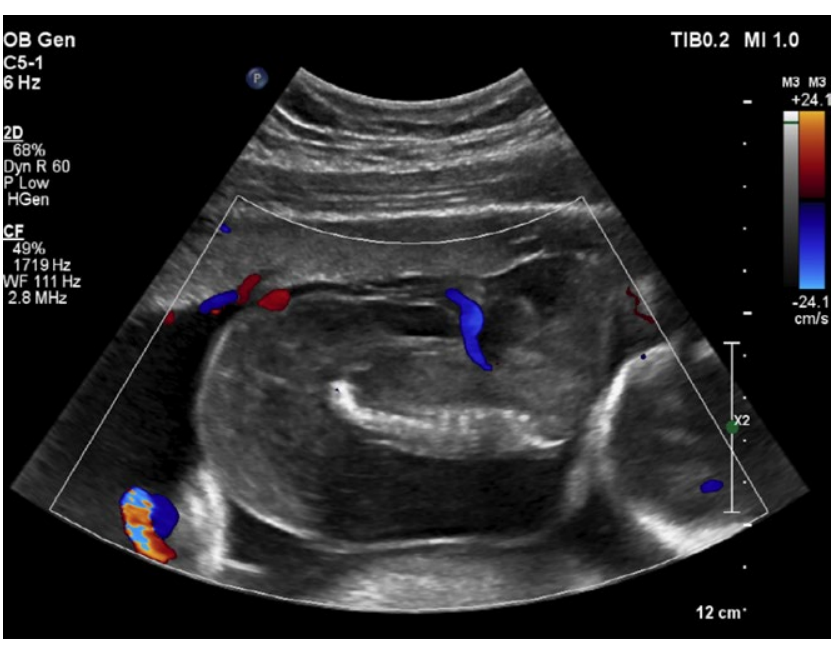

FIGURE 12 Retrograde blood flow into the acardiac twin in a case of twin reversed arterial perfusion sequence.

ultrasonography, the acardiac twin can be misdiagnosed as a fetal demise owing to a lack of cardiac activity on real-time scanning. ${ }^{56}$ Any case of first-trimester fetal demise in monochorionic twins should have a Doppler evaluation for reversal of flow in the umbilical artery in the demised twin to rule out TRAP sequence. ${ }^{56}$ If TRAP is diagnosed, serial ultrasonography examinations should be performed to monitor the relative size of the acardiac twin and the heart function of the pump twin. ${ }^{30}$

The pump twin is at increased risk of perinatal mortality (up to 55\%) owing to high-output cardiac failure caused by the cardiac demands of supporting the acardiac twin and prematurity associated with polyhydramnios. ${ }^{55}$ The outcome depends on the relative size of the pump twin and the acardiac twin. The twin weight ratio is calculated by comparing the ratio of the acardiac twin to the pump twin, using a prolated ellipsoid formula (width $\times$ height $\times$ length $[$ in $\mathrm{cm}] \times 0.523$ ) to estimate the acardiac twin's mass. ${ }^{57}$ If the size of the acardiac twin is more than $50 \%$ of that of the pump twin, procedures that halt the flow of blood to the acardiac twin can lead to better outcomes with $80 \%$ survival of the pump twin. ${ }^{55,57}$ When a diagnosis of TRAP occurs, referral to a fetal therapy center is important to discuss interventions, including cord coagulation or radiofrequency ablation. ${ }^{57}$ Careful anatomic survey of the pump twin should be undertaken because there is a $5 \%-10 \%$ risk of structural anomalies, most commonly congenital heart disease. ${ }^{56}$ Amniocentesis should be offered in cases of TRAP owing to the $9 \%$ risk of chromosomal anomalies. ${ }^{58}$

\section{3 | Monoamniotic/monochorionic twins}

The diagnosis of monoamniotic twins is determined by the lack of an amniotic membrane separating the fetuses in a monochorionic gestation. As mentioned above, the intertwin membrane is often thin and can be difficult to visualize before 12 weeks. If it is not visualized on the initial ultrasonography, the intertwin membrane should continue to be looked for on subsequent scans. Monoamniotic twins can have cord entanglement, which can help confirm the diagnosis (Fig. 13). ${ }^{59}$

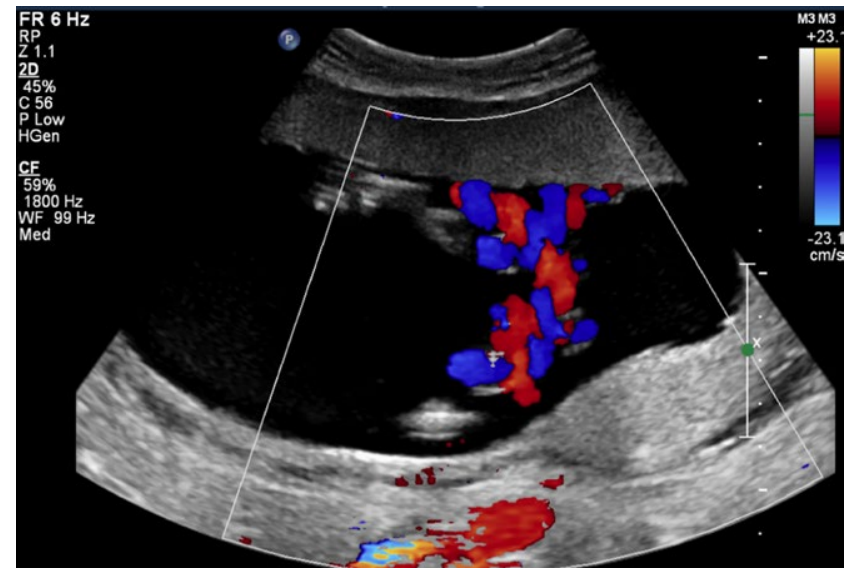

FIGURE 13 Monoamniotic/monochorionic twin gestation in the second trimester with cord entanglement.

Interestingly, the incidence of female fetuses in monoamniotic gestations is higher (>70\%). ${ }^{60}$ This is thought to be related to $\mathrm{X}$ inactivation in female embryos, which causes a slight temporal delay in the twinning process, with a bias toward monoamnionicity. ${ }^{60}$ Historically, monoamniotic twins had perinatal mortality rates as high as $68 \%{ }^{61}$ This was mostly attributed to umbilical cord entanglement but was also influenced by congenital anomalies and prematurity. ${ }^{61}$ With the current practice of intensive fetal surveillance beginning with intent for intervention, survival is approximately $80 \% .{ }^{59}$ Both inpatient and outpatient monitoring have been noted to have similar outcomes. ${ }^{62}$ Among pregnancies that achieve a gestational age consistent with anticipated potential viability, the perinatal mortality rate is more closely related to gestational age at delivery and the presence of anomalies.

Monoamniotic gestations have a significantly higher risk of congenital anomalies (10\%-30\%) and congenital heart defects (4\%). ${ }^{63}$ A detailed anatomic survey coupled with fetal echocardiogram is therefore appropriate.

Although small, there is a $6 \%$ risk of TTTS in monoamniotic twins, which is most probably related to the increased presence of arterioarterial anastomoses and fewer deep arteriovenous anastomoses. ${ }^{63,64}$ The usual criteria of polyhydramnios and oligohydramnios cannot be used for the diagnosis of TTTS in light of the shared single sac. Thus, a maximum vertical pocket greater than $8 \mathrm{~cm}$ before 20 weeks of gestation or greater than $10 \mathrm{~cm}$ after 20 weeks, along with discordant bladder filling, is used to diagnose TTTS.

\subsection{Conjoined twins}

Conjoined twins occur in less than $1 \%$ of monozygotic twins and have a higher incidence in Southeast Asia and Africa. ${ }^{65}$ Similar to monoamniotic/monochorionic twins, most conjoined twin live births are female, with a 3:1 female-to-male ratio. Conjoined twins should be suspected in a monochorionic/monoamniotic twin pregnancy where the fetuses hold the same relative position to each other throughout the ultrasonography. ${ }^{66}$ Other ultrasonography findings suggesting conjoined twins include more than three vessels in the umbilical cord, 

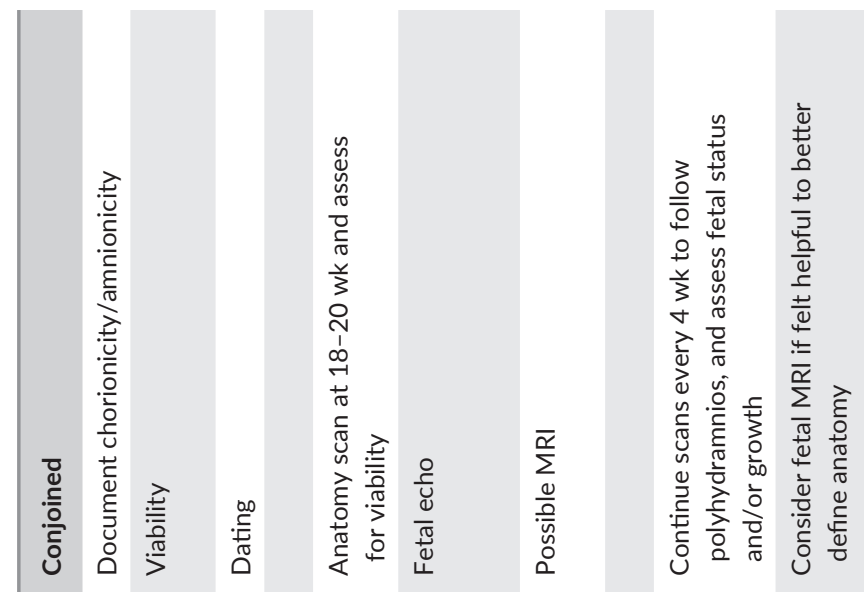

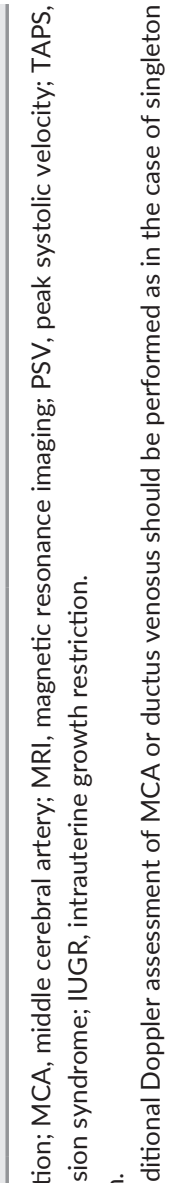
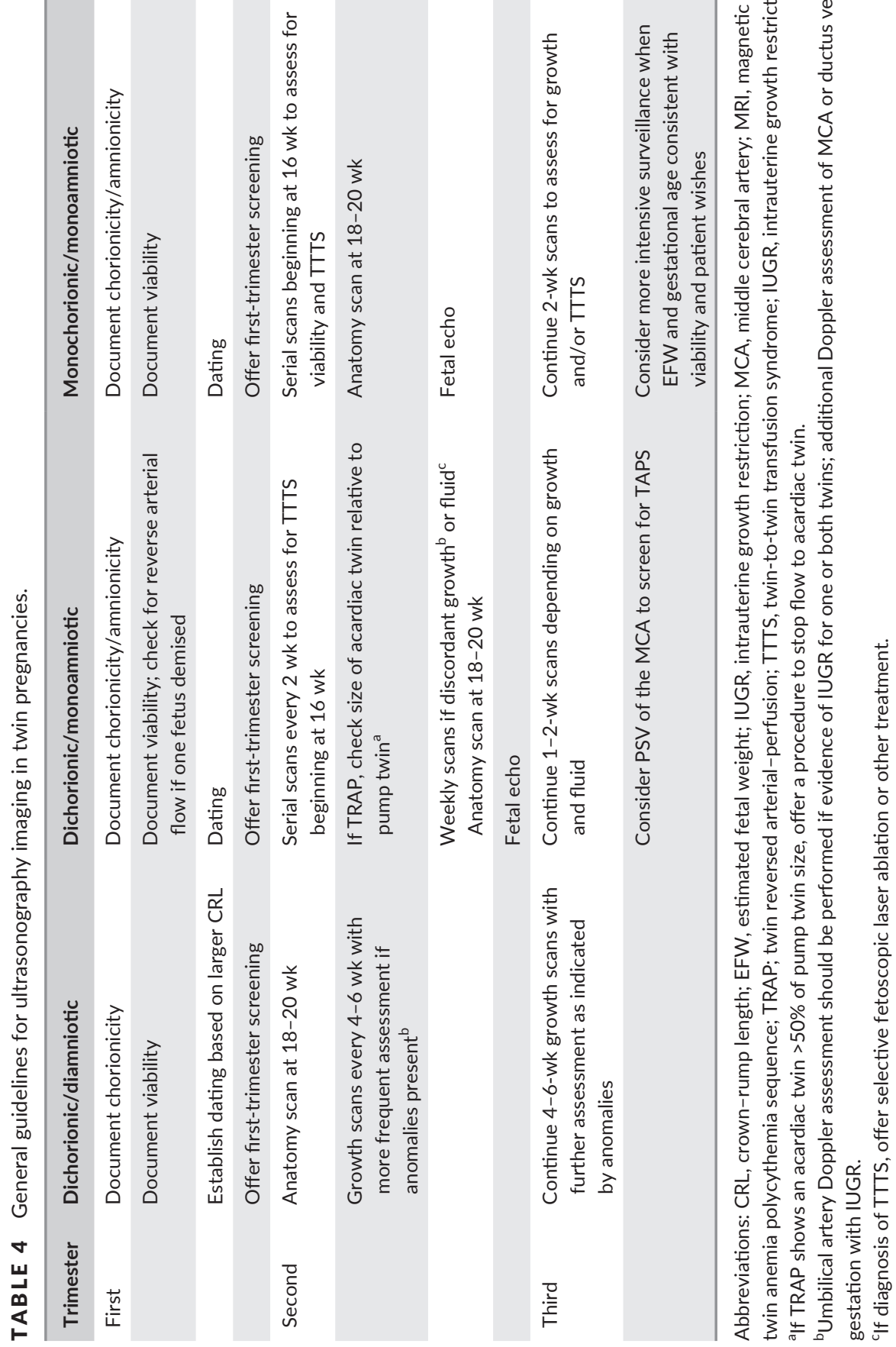
hyperflexion of the spine, and bifid appearance of the fetal pole. ${ }^{67}$ After 8 weeks of gestation, fetal activity typically increases, allowing for improved differentiation between monoamniotic twins and conjoined twins. ${ }^{67}$

Classification of conjoined twins is based on the most prominent site of union. ${ }^{68}$ Conjoined twins are specified into eight types: cephalopagus (fused from vertex to umbilicus), thoracopagus (ventrally from upper thorax to umbilicus), omphalopagus (ventrally in the abdomen), ischiopagus (umbilicus to large conjoined pelvis), parapagus (ventrolateral fusion sharing umbilicus, lower abdomen, pelvis, and genitourinary tract), craniopagus (any part of skull), pyopagus (dorsally sharing sacrococcygeus and perineum), and rachipagus (dorsal fusion that can extend from occiput down to above sacrum). ${ }^{69,70}$

Conjoined twins tend to have more anomalies than non-conjoined monozygotic twins. Malformations occurring in conjoined twins are not only related to junction regions, but also develop away from junctional sites. ${ }^{71}$ Additional imaging modalities, including echocardiogram and magnetic resonance imaging, have been used to assist in delineating shared anatomy in order to optimize counseling on management and planning for delivery and postnatal care. ${ }^{72}$

The prognosis for conjoined twins is poor. For ongoing pregnancies, there is a $10 \%-50 \%$ risk of IUFD, and fewer than half of live-delivered twins survive, ${ }^{68,71}$ with a third dying within 24 hours of delivery. ${ }^{72,74}$ Separation is unlikely to be successful and typically not attempted in twins with complex cardiac fusion or extensive cerebral fusion. ${ }^{69}$ Thoracopagus and parapagus twins have the lowest survival rate after separation, while craniopagus and pyopagus twins have the highest survival rate. ${ }^{73}$ Rachipagus is extremely rare with limited outcome data, and cephalopagus has extensive cerebral fusion that cannot be separated. Postnatal management typically includes non-operative management with comfort care, emergency separation, or planned elective separation, which ideally occurs at 2-4 months of age. ${ }^{68}$

\section{4 | CONCLUSION}

All twin gestations have an increased risk of prematurity and other adverse events. Although prematurity is responsible for most of the morbidity and mortality observed among multiple gestations, monochorionic gestations have a markedly higher risk of adverse events. These problems are secondary to the considerably increased risk of congenital anomalies, sIUGR, and TTTS, which all potentially further increase the risk of prematurity. Although TRAP pregnancies, monochorionic/monoamniotic gestations, and conjoined twins are all relatively rare, they have even more significant rates of morbidity and mortality. If a higher-order multiple gestation (i.e., triplets or more) is diagnosed, chorionicity for the whole gestation must be determined. A monochorionic pair can occur within the triplet or higher gestation and markedly increases the risk of complications within the pregnancy. A monochorionic twin pair within a higher-order multiple gestation should be followed in the same way as any monochorionic twin pair.

The use of ultrasonography to appropriately diagnose twin gestations is central to providing proper counseling and care to parents presenting with a multiple gestation. An abbreviated overview of ultrasonography management is presented in Table 4. There must be a strong recognition that "twins" is an incomplete label: the diagnosis must include chorionicity-namely, dichorionic, monochorionic, or unknown (for women who present late for evaluation). ${ }^{75}$ Once a correct diagnosis is made, the optimal care for the pregnancy can be delineated. This care should aim to provide counseling about the true risks for the gestation, to establish accurate expectations, and to pursue the appropriate ultrasonography surveillance to optimize the outcome of the pregnancy.

\section{AUTHOR CONTRIBUTIONS}

JS, MCT, and DRB contributed to the design, editing, and preparation of the review manuscript.

\section{CONFLICTS OF INTEREST}

The authors have no conflicts of interest.

\section{REFERENCES}

1. Pison G, Monden C, Smits J. Twinning rates in developed countries: Trends and explanations. Popul Dev Rev. 2015;41:629-649.

2. Heino $A$, Gissler M, Hindori-Mohangoo AD, et al. Variations in multiple birth rates and impact on perinatal outcomes in Europe. PLOS ONE. 2016;11:e0149252.

3. Benirschke K, Burton GJ, Baergen RN. Multiple pregnancies. In: Benirschke K, Burton GJ, Baergen RN, eds: Pathology of the Human Placenta. Berlin, Heidelberg: Springer Berlin Heidelberg; 2012: 761-880.

4. Cameron $\mathrm{AH}$. The Birmingham twin survey. Proc $R$ Soc Med. 1968;61:229-234

5. Kawachiya S, Bodri D, Shimada N, Kato K, Takehara Y, Kato O. Blastocyst culture is associated with an elevated incidence of monozygotic twinning after single embryo transfer. Fertil Steril. 2011;95: 2140-2142.

6. Maruotti GM, Saccone G, Morlando M, Martinelli P. First-trimester ultrasound determination of chorionicity in twin gestations using the lambda sign: A systematic review and meta-analysis. Eur J Obstet Gynecol Reprod Biol. 2016;202:66-70.

7. Hill LM, Chenevey P, Hecker J, Martin JG. Sonographic determination of first trimester twin chorionicity and amnionicity. J Clin Ultrasound. 1996;24:305-308

8. Finberg HJ. The "twin peak" sign: Reliable evidence of dichorionic twinning. J Ultrasound Med. 1992;11:571-577.

9. Shetty A, Smith AP. The sonographic diagnosis of chorionicity. Prenat Diagn. 2005;25:735-739.

10. Bessis R, Papiernik E. Echographic imagery of amniotic membranes in twin pregnancies. Prog Clin Biol Res. 1981;69A:183-187.

11. Bora SA, Papageorghiou AT, Bottomley C, Kirk E, Bourne T. Reliability of transvaginal ultrasonography at 7-9 weeks' gestation in the determination of chorionicity and amnionicity in twin pregnancies. Ultrasound Obstet Gynecol. 2008;32:618-621.

12. Monteagudo A, Timor-Tritsch IE, Sharma S. Early and simple determination of chorionic and amniotic type in multiple gestation in the first 14 weeks by high frequency transvaginal ultrasonography. Am J Obstet Gynecol. 1994;170:824-829.

13. Carroll SG, Soothill PW, Abdel-Fattah SA, Porter H, Montague I, Kyle PM. Prediction of chorionicity in twin pregnancies at 10-14 weeks of gestation. Br J Obstet Gynaecol. 2002;109:182-186. 
14. Sepulveda W, Sebire NJ, Hughes K, Kalogeropoulos A, Nicolaides KH Evolution of the lambda or twin-chorionic peak sign in dichorionic twin pregnancies. Obstet Gynecol. 1997;89:439-441.

15. Lee YM, Cleary-Goldman J, Thaker HM, Simpson LL. Antenatal sonographic prediction of twin chorionicity. Am J Obstet Gynecol. 2006;195:863-867.

16. Lopriore E, Sueters M, Middeldorp JM, Klumper F, Oepkes D, Vandenbussche FP. Twin pregnancies with two separate placental masses can still be monochorionic and have vascular anastomoses. Am J Obstet Gynecol. 2006;194:804-808.

17. Bracero LA, Byrne DW. Ultrasound determination of chorionicity and perinatal outcome in twin pregnancies using dividing membrane thickness. Gynecol Obstet Invest. 2003;55:50-57.

18. Khalil A, Rodgers M, Baschat A, et al. ISUOG practice guidelines: Role of ultrasound in twin pregnancy. Ultrasound Obstet Gynecol. 2016;47:247-263.

19. Committee on Obstetric Practice, The American Institute of Ultrasound in Medicine, and the Society for Maternal-Fetal Medicine. Committee Opinion No 700: Methods for estimating the due date. Obstet Gynecol. 2017;129:e150-e154.

20. Cleary-Goldman J, Berkowitz RL. First trimester screening for Down syndrome in multiple pregnancy. Semin Perinatol. 2005;29:395-400.

21. Sarno L, Revello R, Hanson E, Akolekar R, Nicolaides KH. Prospective first-trimester screening for trisomies by cell-free DNA testing of maternal blood in twin pregnancy. Ultrasound Obstet Gynecol. 2016:47:705-711.

22. Committee on Practice Bulletins-Obstetrics, Committee on Genetics, and Society for Maternal-Fetal M. Practice bulletin no. 163: Screening for fetal aneuploidy. Obstet Gynecol. 2016;127:e123-e137.

23. Gregg AR, Skotko BG, Benkendorf JL, et al. Noninvasive prenatal screening for fetal aneuploidy, 2016 update: A position statement of the American College of Medical Genetics and Genomics. Genet Med. 2016;18:1056-1065.

24. Glinianaia SV, Rankin J, Wright C. Congenital anomalies in twins: A register-based study. Hum Reprod. 2008;23:1306-1311.

25. Boyle B, McConkey R, Garne E, et al. Trends in the prevalence, risk and pregnancy outcome of multiple births with congenital anomaly: A registry-based study in 14 European countries 1984-2007. Br J Obstet Gynaecol. 2013;120:707-716.

26. Weis MA, Harper LM, Roehl KA, Odibo AO, Cahill AG. Natural history of placenta previa in twins. Obstet Gynecol. 2012;120:753-758.

27. Costa-Castro T, Zhao DP, Lipa M, et al. Velamentous cord insertion in dichorionic and monochorionic twin pregnancies - Does it make a difference? Placenta. 2016:42:87-92.

28. Victoria A, Mora G, Arias F. Perinatal outcome, placental pathology, and severity of discordance in monochorionic and dichorionic twins. Obstet Gynecol. 2001;97:310-315.

29. Klatt J, Kuhn A, Baumann M, Raio L. Single umbilical artery in twin pregnancies. Ultrasound Obstet Gynecol. 2012;39:505-509.

30. Emery SP, Bahtiyar MO, Moise KJ; North American Fetal Therapy N. The North American Fetal Therapy Network consensus statement: Management of complicated monochorionic gestations. Obstet Gynecol. 2015;126:575-584.

31. Paepe ME. Examination of the twin placenta. Semin Perinatol. 2015;39:27-35

32. Hillman SC, Morris RK, Kilby MD. Co-twin prognosis after single fetal death: A systematic review and meta-analysis. Obstet Gynecol. 2011;118:928-940.

33. D'Antonio F, Khalil A, Pagani G, Papageorghiou AT, Bhide A, Thilaganathan B. Crown-rump length discordance and adverse perinatal outcome in twin pregnancies: Systematic review and metaanalysis. Ultrasound Obstet Gynecol. 2014;44:138-146.

34. Sebire NJ, Snijders RJ, Hughes K, Sepulveda W, Nicolaides KH. Screening for trisomy 21 in twin pregnancies by maternal age and fetal nuchal translucency thickness at 10-14 weeks of gestation. Br J Obstet Gynaecol. 1996;103:999-1003.

35. Kagan KO, Gazzoni A, Sepulveda-Gonzalez G, Sotiriadis A, Nicolaides $\mathrm{KH}$. Discordance in nuchal translucency thickness in the prediction of severe twin-to-twin transfusion syndrome. Ultrasound Obstet Gynecol. 2007;29:527-532.

36. Bronsteen $\mathrm{R}$, Whitten $\mathrm{A}$, Balasubramanian $\mathrm{M}$, et al. Vasa previa: Clinical presentations, outcomes, and implications for management. Obstet Gynecol. 2013;122(2 Pt 1):352-357.

37. Springer S, Mlczoch E, Krampl-Bettelheim E, et al. Congenital heart disease in monochorionic twins with and without twin-to-twin transfusion syndrome. Prenat Diagn. 2014;34:994-999.

38. Emery SP, Bahtiyar MO, Dashe JS, et al. The North American Fetal Therapy Network consensus statement: Prenatal management of uncomplicated monochorionic gestations. Obstet Gynecol. 2015;125:1236-1243.

39. Bahtiyar MO, Emery SP, Dashe JS, et al. The North American Fetal Therapy Network consensus statement: Prenatal surveillance of uncomplicated monochorionic gestations. Obstet Gynecol. 2015;125:118-123.

40. Thorson HL, Ramaeker DM, Emery SP. Optimal interval for ultrasound surveillance in monochorionic twin gestations. Obstet Gynecol. 2011;117:131-135.

41. Quintero RA, Morales WJ, Allen MH, Bornick PW, Johnson PK, Kruger M. Staging of twin-twin transfusion syndrome. J Perinatol. 1999; 19(8 Pt 1):550-555.

42. Roberts D, Neilson JP, Kilby MD, Gates S. Interventions for the treatment of twin-twin transfusion syndrome. Cochrane Database Syst Rev. 2014;(1):CD002073.

43. Emery SP, Hasley SK, Catov JM, et al. North American Fetal Therapy Network: Intervention vs expectant management for stage I twin-twin transfusion syndrome. Am J Obstet Gynecol. 2016;215: 346.e341-346.e347.

44. Senat MV, Deprest J, Boulvain M, Paupe A, Winer N, Ville Y. Endoscopic laser surgery versus serial amnioreduction for severe twin-to-twin transfusion syndrome. N Engl J Med. 2004;351:136-144.

45. Slaghekke F, Kist WJ, Oepkes D, et al. Twin anemia-polycythemia sequence: Diagnostic criteria, classification, perinatal management and outcome. Fetal Diagn Ther. 2010;27:181-190.

46. Beck V, Lewi P, Gucciardo L, Devlieger R. Preterm prelabor rupture of membranes and fetal survival after minimally invasive fetal surgery: A systematic review of the literature. Fetal Diagn Ther. 2012;31:1-9.

47. Snowise S, Mann LK, Moise KJ Jr, Johnson A, Bebbington MW, Papanna R. Preterm prelabor rupture of membranes after fetoscopic laser surgery for twin-twin transfusion syndrome. Ultrasound Obstet Gynecol. 2017;49:607-611.

48. Gordon BJ, Chon AH, Korst LM, Llanes A, Miller DA, Chmait RH. Incidental septostomy after laser surgery for twin-twin transfusion syndrome: Perinatal outcomes and antenatal management. Fetal Diagn Ther. 2017. [preprint]. https://doi.org/10.1159/000485034.

49. van Klink JM, van Steenis A, Steggerda SJ, et al. Single fetal demise in monochorionic pregnancies: Incidence and patterns of cerebral injury. Ultrasound Obstet Gynecol. 2015;45:294-300.

50. Takano M, Nakata M, Murata S, Sumie M, Morita M. Chorioamniotic membrane separation after fetoscopic laser photocoagulation. Fetal Diagn Ther. 2018;43:40-44.

51. Lewi L, Jani J, Blickstein I, et al. The outcome of monochorionic diamniotic twin gestations in the era of invasive fetal therapy: A prospective cohort study. Am J Obstet Gynecol. 2008;199:514.e511514.e518.

52. Gratacos E, Lewi L, Munoz B, et al. A classification system for selective intrauterine growth restriction in monochorionic pregnancies according to umbilical artery Doppler flow in the smaller twin. Ultrasound Obstet Gynecol. 2007;30:28-34. 
53. Tollenaar LS, Slaghekke F, Middeldorp JM, et al. Twin anemia polycythemia sequence: Current views on pathogenesis, diagnostic criteria, perinatal management, and outcome. Twin Res Hum Genet. 2016;19:222-233.

54. Robyr R, Lewi L, Salomon LJ, et al. Prevalence and management of late fetal complications following successful selective laser coagulation of chorionic plate anastomoses in twin-to-twin transfusion syndrome. Am J Obstet Gynecol. 2006;194:796-803.

55. Moore TR, Gale S, Benirschke K. Perinatal outcome of forty-nine pregnancies complicated by acardiac twinning. Am J Obstet Gynecol. 1990;163:907-912.

56. Hanafy A, Peterson CM. Twin-reversed arterial perfusion (TRAP) sequence: Case reports and review of literature. Aust N Z J Obstet Gynaecol. 1997;37:187-191.

57. Lee $\mathrm{H}$, Bebbington $\mathrm{M}$, Crombleholme TM. North American Fetal Therapy Network: The NorthAmerican Fetal Therapy Network Registry data on outcomes of radiofrequency ablation for twin-reversed arterial perfusion sequence. Fetal Diagn Ther. 2013;33:224-229.

58. Healey MG. Acardia: Predictive risk factors for the co-twin's survival. Teratology. 1994;50:205-213.

59. Hack KE, Derks JB, Schaap AH, et al. Perinatal outcome of monoamniotic twin pregnancies. Obstet Gynecol. 2009;113(2 Pt 1):353-360.

60. Monteiro J, Derom C, Vlietinck R, Kohn N, Lesser M, Gregersen PK. Commitment to $\mathrm{X}$ inactivation precedes the twinning event in monochorionic MZ twins. Am J Hum Genet. 1998;63:339-346.

61. Carr SR, Aronson MP, Coustan DR. Survival rates of monoamniotic twins do not decrease after 30 weeks' gestation. Am J Obstet Gynecol. 1990;163:719-722.

62. Van Mieghem T, De Heus R, Lewi L, et al. Prenatal management of monoamniotic twin pregnancies. Obstet Gynecol. 2014;124: 498-506.
63. Baxi LV, Walsh CA. Monoamniotic twins in contemporary practice: A single-center study of perinatal outcomes. J Matern Fetal Neonatal Med. 2010;23:506-510.

64. UmurA, van Gemert MJ, Nikkels PG. Monoamniotic-versus diamnioticmonochorionic twin placentas: Anastomoses and twin-twin transfusion syndrome. Am J Obstet Gynecol. 2003;189:1325-1329.

65. Fitzgerald EJ, Toi A, Cochlin DL. Conjoined twins. Antenatal ultrasound diagnosis and a review of the literature. Br J Radiol. 1985; 58:1053-1056.

66. Hill LM. The sonographic detection of early first-trimester conjoined twins. Prenat Diagn. 1997;17:961-963.

67. Baken L, Rousian M, Kompanje EJ, et al. Diagnostic techniques and criteria for first-trimester conjoined twin documentation: A review of the literature illustrated by three recent cases. Obstet Gynecol Surv. 2013;68:743-752.

68. Pajkrt E, Jauniaux E. First-trimester diagnosis of conjoined twins. Prenat Diagn. 2005;25:820-826.

69. Pierro A, Kiely EM, Spitz L. Classification and clinical evaluation. Semin Pediatr Surg. 2015;24:207-211.

70. Spencer R. Anatomic description of conjoined twins: A plea for standardized terminology. J Pediatr Surg. 1996;31:941-944.

71. Chen CP, Hsu CY, Su JW, et al. Conjoined twins detected in the first trimester: A review. Taiwan J Obstet Gynecol. 2011;50:424-431.

72. Laifer-Narin S, Budorick NE, Simpson LL, Platt LD. Fetal magnetic resonance imaging: A review. Curr Opin Obstet Gynecol. 2007;19:151-156.

73. Kiely EM, Spitz L. The separation procedure. Semin Pediatr Surg. 2015;24:231-236.

74. Kaufman MH. The embryology of conjoined twins. Childs Nerv Sys. 2004;20:508-525.

75. Moise $\mathrm{KJ} \mathrm{Jr}$, Johnson A. There is NO diagnosis of twins. Am J Obstet Gynecol. 2010;203:1-2. 